\title{
The Effect of Hair Spray Exposure to the Changes in Electrical Properties of Mice Organ
}

\author{
Unggul P. Juswono, Arinto Y.P. Wardoyo, Chomsin S. Widodo, Johan A.E. Noor, Didik R. \\ Santoso
}

\begin{abstract}
Human activities at this time tend to use substances that are pollutants and have an impact on health. Pollutants can enter the body through the process of respiration and will disrupt the organ function. Substances that are often used in daily life and potentially as pollutants are hairspray. They contain vinyl acetate and methacrylate complex polymers. Cocamide DEA surfactants in hairspray can cause cancer and produce toxins. The use of hairspray continuously will cause organ damage due to the emergence of secondary metabolites and free radicals. The diagnosis of organ damage in the latest research from various scientists is to utilize the electrical characteristics of the organ. The bioelectric characteristic that can be observed is dielectric constant. Based on the impact of organ damage and suspected changes in organ electrical properties due to exposure to pollutants, a study needs to be conducted to observe changes in the resistivity and dielectric constant in organ tissue in mice exposed to hairspray with cocamide DEA surfactant content. The results showed that the more concentration of exposure given causes increasing the level of damage to the organs. The increasing level of damage is very significant in the changing of the resistivity and dielectric constant value of mice organs. The changing of electrical properties of mice organs is possible due to damage to organ cells caused by increasing reactive oxygen species and free radicals due to oxidation reactions resulting from the interaction of cocamide DEA with cell components.
\end{abstract}

Keywords: Electrical properties; hair spray; mice; organ damage.

\section{INTRODUCTION}

The existence of pollutants in the air around us is very harmful to human health. Pollutants can be in the form of gaseous and particulate matter emissions. Pollutants can enter the body through the respiration and oral process. Substances that are frequently used in daily life and have the potential as a pollutant is a hairspray. The presence of pollutants in the body will be able to disrupt the function of organs [1-4]. Organs are often affected by pollutants in the kidney as a major organ in the excretory system, lungs as respiratory organs, the liver plays an important role in the process of detoxification and blood as the largest in the body fluid. The level of damage to organs caused by particulate matter in pollutants strongly influenced by particle size $[5,6]$. Based on its size, the particles can be classified into coarse

Revised Manuscript Received on January 2, 2020.

* Correspondence Author

Unggul P. Juswono*, Physics Department, Brawijaya University, J1 Veteran, Malang, East Java, Indonesia. Email: unggul-pj@ub.ac.id

Arinto Y. P. Wardoyo, Physics Department, Brawijaya University, Jl. Veteran, Malang, East Java, Indonesia. Email: a.wardoyo@ub.ac.id

Chomsin S. Widodo, Physics Department, Brawijaya University, Jl Veteran, Malang, East Java, Indonesia. Email: chomsin @ub.ac.id

Johan A.E. Noor, Physics Department, Brawijaya University, Jl. Veteran, Malang, East Java, Indonesia. Email: jnoor@ub.ac.id

Didik R. Santoso, Physics Department, Brawijaya University, Jl. Veteran, Malang, East Java, Indonesia. Email: dieks@ub.ac.id particles, fine particles, and ultrafine particles. Ultrafine particles provide a greater effect than the larger particles.

Hairspray is a product that is used to create the shape and style hair. Hairspray prevents air moisture levels in the hair where changes in humidity will cause the loss of or damage to the hair. The main ingredient of hairspray is a complex polymer of vinyl acetate and methacrylate. The solvent of the polymer is water mixed with diethanolamine surfactant resin which also works as an emulsifying of hairspray ingredient. Diethanolamine (DEA) that is commonly used as an emulsifier is cocamide DEA. The entry of hairspray material into the body can have a bad effect on the organs of the body. The polymeric material in hairspray can cause adhesion of respiratory ciliary epithelium so that respiratory mucus cannot be transported and is a place for fungal growth in the lungs [7].

Besides, the diagnosis of organ damage can be done by utilizing the change in the electrical characteristics of the organ. In particular, biological systems in living organisms can be characterized by its bioelectric characteristics. Bioelectric characteristics can be observed from the magnitude of the impedance, capacitance, inductance, the dielectric constant and electrical conductivity of organs [8]. The electrical properties of an organ can be used as a source of information about good health or bad an organ. Some studies show there is a difference between the electrical characteristics of normal and abnormal tissues [9,10].

Due to the correlation between cellular damage to the electrical characteristics of the organ is necessary to do research on the effects of exposure to hairspray on the extent of damage and changes in the electrical properties of the organ. This study aimed to analyze the effect of exposure to hairspray to the cocamide DEA on the electrical properties of the dielectric constant and resistivity changes of the organ tissue of mice (Mus musculus). The benefit of this research is the sufficient information on the effect of hairspray exposure to changes in the electrical properties of the organs of mice and can be taken into consideration in granting the use of cocamide DEA in hairspray. In addition, the public can be careful in using hairspray to avoid the negative effects of using hairspray.

\section{MATERIALS AND METHODS}

\section{A. Animals and Treatments}

Steps being taken in the research started from the acclimatization seventy mice. Acclimatization was done so that animal testing can adapt to new conditions that were occupied during the experiment. 
The population in this study were seventy male mice with ten mice as controls and sixty mice as treatment. The number of sixty mice were divided into five populations for treatment of exposure to hairspray. There are 2 kinds of treatment of experimental animals are treated with negative control $(\mathrm{K})$ and treatment with exposure to hairspray (KS). Hairspray exposure in mice was conducted by entering the mice into a closed chamber. Variations of spray exposure were 1, 2, 3, 4 and 5 sprays to each chamber. Each chamber contained ten mice. The exposure process lasted 20 minutes with the state of the closed chamber. This was intended so that no airflow in and out of the chamber. After twenty minutes, the chamber was opened and mice were returned to the cage. This treatment was carried out every day for 30 days. The next stage was the surgery of mice and organ taking. Surgery was performed in accordance with standard procedures and in accordance with the code of conduct of research using animals. After surgery, the organs were taken and divided for purposes of making preparations, test the resistivity and dielectric properties of organs.

\section{B. Histological Examination}

The level of organ damage was calculated based on the microscopic picture of the organ. Observation of the damage was done by using the BX-51 Computer Binocular Microscope with the magnification of 400x. The calculation of the damage was done on ten widely different viewpoints chosen randomly on each preparation. Mice organ damage level $(D L)$ was calculated using:

$$
D L=[\text { [damage cells / Eobserved cells }] \times 100 \%
$$

\section{Resistivity and Dielectric Constant Test}

All The measurements of resistivity and dielectric properties of organs were done using an LCR meter Instek GW-816 type (Fig. 1). The organ samples were tested in the frequency of $100 \mathrm{~Hz}$ to $2000 \mathrm{~Hz}$. They were placed on the test site with a certain cross-sectional area $A$ and tube length $d$.

Organ resistivity value $(\rho)$ was calculated using the equation:

$$
\rho=\frac{R \times A}{d}
$$

While the value of the dielectric constant $\left(\varepsilon^{\prime}\right)$ was calculated using the equation:

$$
\varepsilon^{\prime}=\frac{C d}{\epsilon_{0} A}
$$

where:

$R \quad=$ resistance of sample $(\Omega)$ measured by LRC meter

$\varepsilon^{\prime}=$ dielectric constant

$C$ = capacitor capacity (Farad) measured by LRC meter

$\epsilon_{\circ}=$ vacuum permittivity $\left(8.85 \times 10^{-12} \mathrm{~F} / \mathrm{m}\right)$

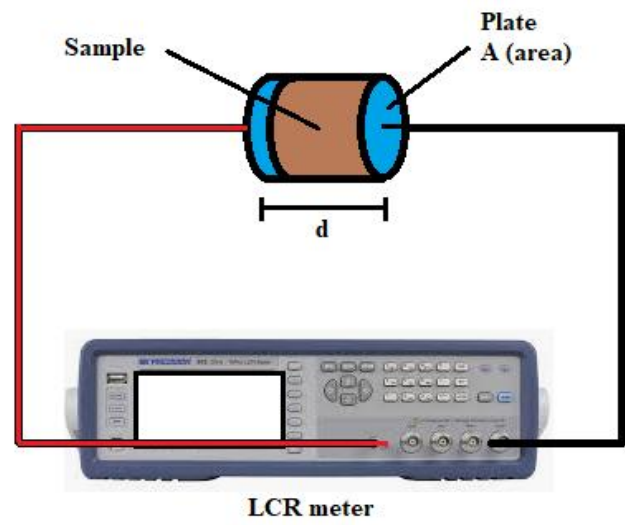

Fig. 1. Schematic for sample measurement

\section{RESULTS AND DISCUSSION}

In this study, the data obtained are the percentage of cell damage, resistivity and dielectric constants of organs. The percentage of cell damage is calculated based on the number of damaged cells divided by the total number of cells from the organs of mice. The amount of hairspray contained in the chamber with the number of sprays is shown in Fig. 2. The level of damage in the organs under normal conditions and in the treatment state (hair spray) is shown in Fig. 3. Then, the relationship of the changes in the level of damage with the changes in resistivity and dielectric constants of organs are shown in Fig. 4 and Fig. 5.

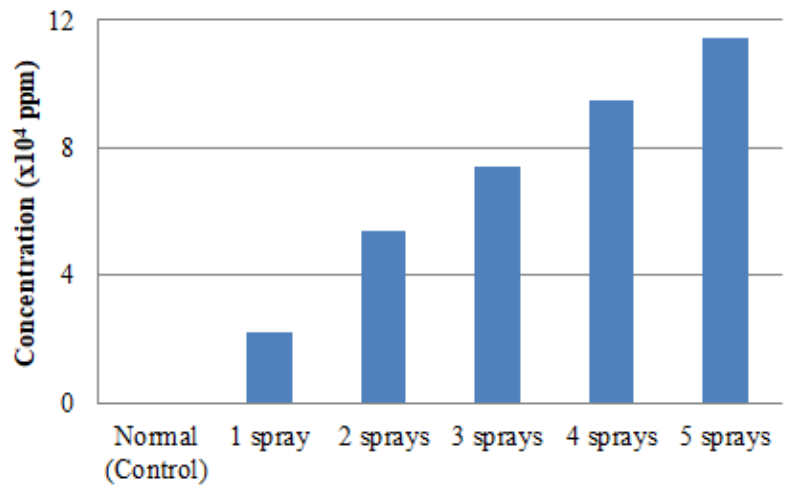

Fig. 2. The amount of the content of hairspray in the chamber with the number of sprays

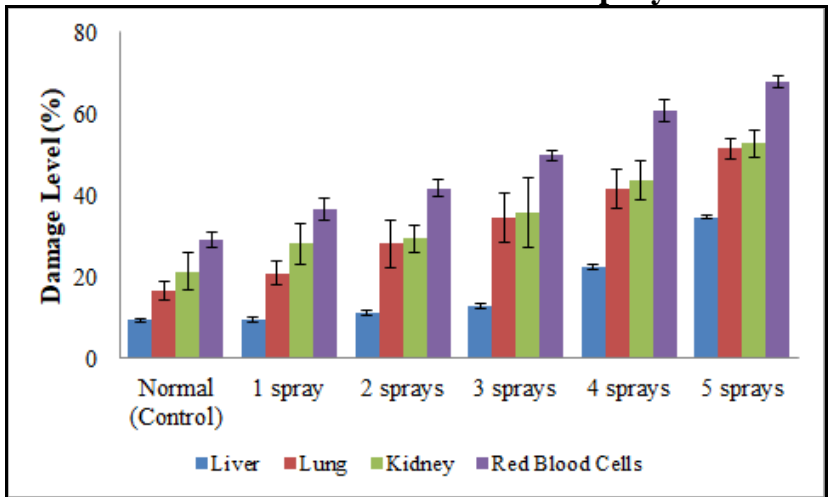

Fig. 3. The level of damage of organs under control and treated groups 


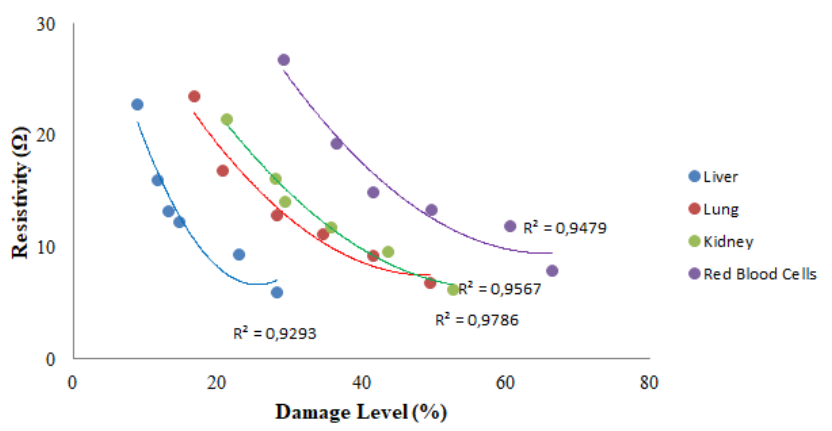

Fig. 4. Relationship between changes in the level of damage with changes in organ resistivity

Mice organ damage can be seen based on a decrease in the value of the dielectric constant. The dielectric constant describes the degree of polarization of a material.
Polarization is defined as the ability to polarize an electric charge contained in a dielectric material due to an external electric field [11]. Polar materials have a relatively large electric dipole moment. This polarization results in a parallel orientation of the electric dipole. A dipole moment can be interpreted as a pair of charges which have opposite charges and are separated over a certain distance. The direction of the dipole moment is from the negative charge to the positive charge [11]. This dipole moment will determine the amount of polarization that occurs. The level of organ polarization is determined by the magnitude of the moment of the dipole molecule in the organ and the number of healthy cells and damaged cells

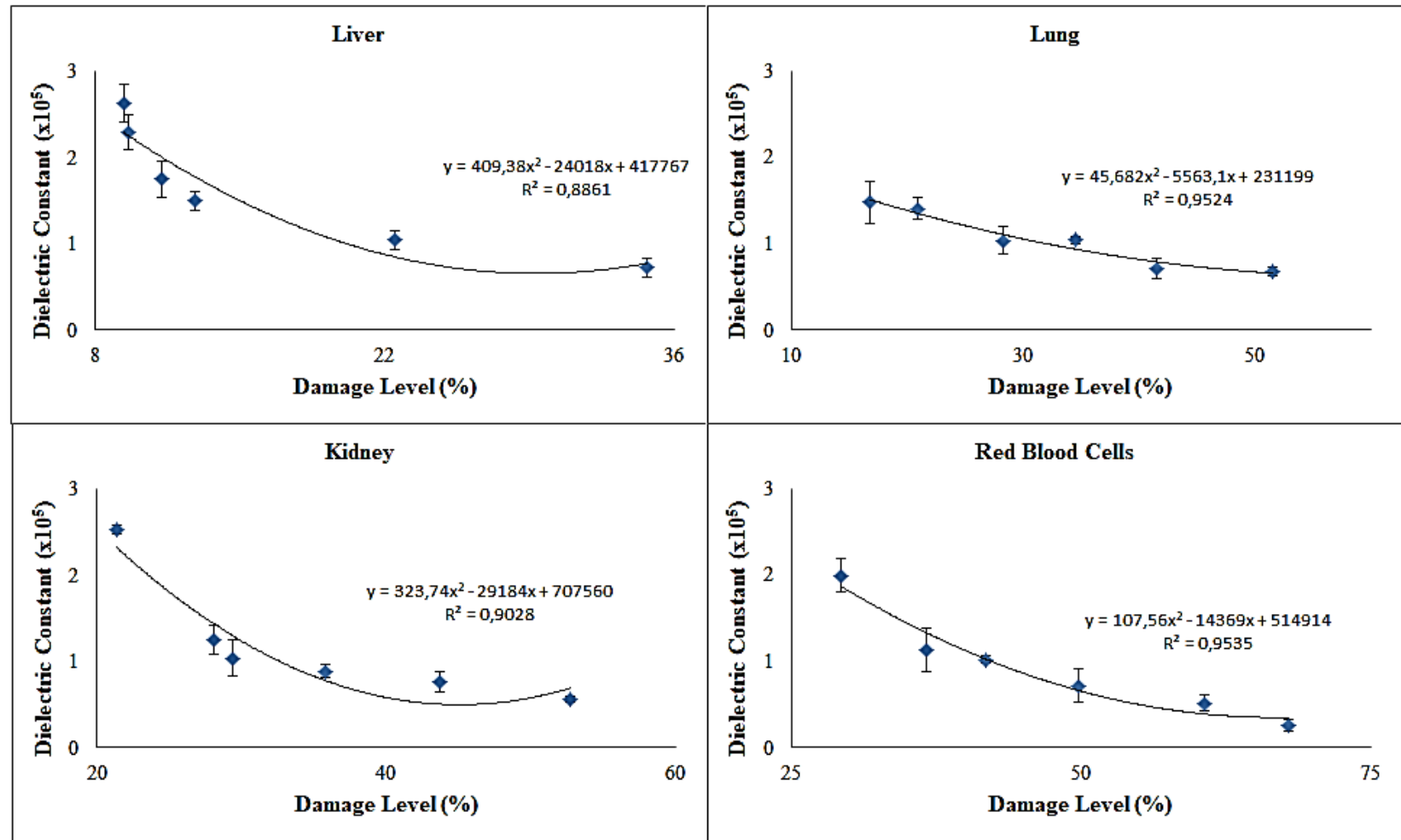

Fig. 5. The relationship between damage level and dielectric constant of the mice's organs

The total value of the dipole moment of a material depends on a value of dipole moments of the individual atoms making up the material, the external electric field strength, and the number of atoms or molecules. Organ damage or reduced healthy cells in the organ will affect the polarization that occurs. The healthier cells in the organ, the greater the polarization that will occur. This will cause higher dielectric constant values. Conversely, the more cells are damaged the less polarization that occurs so the dielectric constant value is lower.

In the cell, there is a membrane that serves as a barrier between the inside and outside of cells as well as ion transport regulators. Cell membranes are composed of lipid bilayer and protein molecules. Lipid bilayer containing clusters of hydrocarbons that are as insulator (hydrophobic) and a cluster of phosphate which is polar (hydrophilic). Proteins in the membrane serve as transport of ions and are semi-permeable membranes. With such an arrangement, the membrane can be described as a parallel of RC electric circuit. If the membrane is damaged due to active ingredients, toxins, and free radicals, the $\mathrm{R}$ and $\mathrm{C}$ values of the membrane decrease and this condition is in accordance with the results of the study. A decrease in the dielectric constant indicates that the organ is increasingly non-polar. The dielectric constant is also dependent on electricity susceptibility. Susceptibility describes the level of polarization of a material. So, the greater the value of the dielectric constant, the material will be more easily polarized.

Cocamide DEA is a foam-enhancing surfactant substance [12]. Cocamide DEA consists of two compounds: cocamide and diethanolamine. Cocamide DEA has both hydrophilic and hydrophobic properties. Part fatty acid compound (cocoakil R) is hydrophobic, while the head is hydrophilic. Cocoakil on cocamide DEA is $\mathrm{CH}_{3}\left(\mathrm{CH}_{2}\right)_{\mathrm{n}} \mathrm{CH}_{2}$ which is a compound of the amide. If there is a buildup of cocamide DEA concentrations in 
organs, there will be a breakdown of

cocamide DEA and activate the $\mathrm{RCO}_{-}$group. The $\mathrm{RCO}_{-}$ group is a free radical group that represents oil acid radicals. If there is a diffusion of a group RCO_ into the red blood cells, then this group will react with hemoglobin. The reaction will cause hemoglobin cannot bind to oxygen. Hemoglobin which should bind to oxygen will be inhibited by RCO_ which acts as a free radical. The interaction between hemoglobin with the RCO group resulted in the oxidation of hemoglobin into methemoglobin. The oxidation reaction will spontaneously generate superoxide $\left(\mathrm{O}_{2}^{-}\right)$(Fig. 6). Methemoglobin is a condition in which red blood cells do not want to bind to oxygen [13].

$$
\mathrm{HbFe}^{++}+\mathrm{O}_{2} \rightarrow \mathrm{HbFe}^{+++} \mathrm{O}_{2}^{-} \rightarrow \mathrm{HbFe}^{+++}+\mathrm{O}_{2}^{-}
$$

Fig. 6. The oxidation reaction of hemoglobin into methemoglobin

Superoxide is an oxidizing compound derived from oxygen that is in a group of reactive oxygen species (ROS). Superoxide is very reactive that is easily cross-linked (cross-link) to DNA, protein, and lipids. The cell membrane may be damaged when the oxidative reaction occurs with $\mathrm{O}_{2}^{-}$, such as in blood. Oxidation of membrane lipids can damage, disrupt the fluidity and permeability of cell membranes. Damage to membrane proteins will disrupt the structural activity of enzymes and proteins.

Damage to the membrane will cause the resistance of cells to inhibit the transport of substances or ions in the membrane to be reduced and cause membrane leakage. Leakage occurs at the membrane resulting in an uncontrolled transfer of substances and ion transport imbalance. Increased ion transport will lead to an increase in the ion concentration inside the cell. Increased ion concentration caused the outbreak of the protein composition of the membrane thereby reducing the membrane's ability to store electricity and impede electrical current. Interestingly, the results of this study indicate that the administration of hairspray which has an impact on cell damage will reduce the dipole moment/ reduced polarity of the organs. This will result in decreased susceptibility in organs so that the value of the dielectric constant in damaged organs also decreases. The relationship between susceptibility and dielectric constants is shown by the equation:

$$
C=\frac{\varepsilon_{0}\left[1+\chi_{e}\right) A}{d}
$$

where $\chi_{e}$ is susceptibility whose value is influenced by the number of atoms or molecules involved in polarization and is also influenced by the value of the dipole moment organs.

\section{CONCLUSION}

The more concentration in the exposure treatment causes a higher level of damage to the organs of mice. The increasing level of damage to the organs of mice greatly affects the value of the resistivity and dielectric constant of the organs of mice. The values of resistivity and dielectric constant of organs decreased along with the increasing damage that occurs in mice. The increase in organ cell damage may be caused by the increasing occurrence of ROS and free radicals in cells. Increased ROS and free radicals within the cell are possible due to the oxidation reaction of the cocamide DEA result of interaction with components of the cell components.

\section{REFERENCES}

1. A. Nemmar, B. Vanquickenborne, D. Dinsdale, M. Thomeer, H Hoylaerts, H. Vanbilloen, L. Montelmans, and B. Nemery, "Passage of inhaled particles into the blood circulation in humans," Circulation, vol. 105, 2002, pp. 411-414.

2. M. Semmler, J. Seitz, F. Erbe, P. Mayer, J. Heyder, G. Oberdörster, and Kreyling, "Long-term clearance kinetics of inhaled ultrafine insoluble iridium particles from the rat lung, including transient translocation into secondary organs," Inhal. Toxicol., vol. 16, 2004, pp. 453-459.

3. N.L. Mills, N. Amin, S.D. Robinson, A. Anand, J. Davies, D. Patel, J.M. De La Fuente, F.R. Cassee, N.A. Boon, W. MacNee, A.M. Millar, K. Donaldson, and D.E. Newby, "Do inhaled carbon nanoparticles translocate directly into the circulation in humans?", Am. J. Respir. Crit. Care Med., vol. 173, 2006, pp. 426-431.

4. X. Jia, Y. Hao, and X. Guo, "Ultrafine carbon black disturbs heart rate variability in mice," Toxicol. Lett., vol. 211, 2012, pp. 274-280.

5. A.Y.P. Wardoyo, U.P. Juswono, and J.A.E. Noor, "How exposure to ultrafine and fine particles of car smoke can alter erythrocyte forms of male mice,” Polish J. Environ. Stud., vol. 28, 2019, pp. 2901-2910.

6. A.Y.P. Wardoyo, U.P. Juswono, and J.A.E. Noor, "Varied dose exposures to ultrafine particles in the motorcycle smoke cause kidney cell damages in male mice," Toxicol. Reports, vol. 5, 2018, pp. 383-389.

7. J. Lang, H.F. Zech, F. Veit, G. Lasczkowski, and R. Dettmeyer, "Chronic abuse of hairspray by inhalation and sudden death of a 20 -year-old woman,” Rom. J. Leg. Med., vol. 23, 2015, pp. 285-288.

8. Y.H. Lee, J. Lee, D.R. Kang, J. Hong, and J. Lee, "Bioelectrical impedance analysis values as markers to predict severity in critically ill patients," J. Crit. Care., vol. 40, 2017, pp. 103-107.

9. M. Asklöf, P. Kjølhede, N.B. Wodlin, and L. Nilsson, "Bioelectrical impedance analysis; a new method to evaluate lymphoedema, fluid status, and tissue damage after gynaecological surgery - A systematic review," Eur. J. Obstet. Gynecol. Reprod. Biol., vol. 228, 2018, pp. 111-119.

10. G. Moschopoulou, A.M. Dourou, A. Fidaki, and S.E. Kintzios, "Assessment of pesticides cytoxicity by means of bioelectric profiling of mammalian cells, Environ. Nanotechnology," Monit. Manag., vol. 8, 2017, pp. 254-260.

11. M. Al Ahmad, Z. Al Natour, F. Mustafa, and T.A. Rizvi, "Electrical characterization of normal and cancer cells,” IEEE Access, vol. 6, 2018, pp. 25979-25986.

12. F.A. Andersen, "Final report on the safety assessment of Cocamide MEA," Int. J. Toxicol., vol. 18, 1999, pp. 9-16.

13. M.L. Alvarado-Noguez, C. Hernández-Aguilar, A. Cruz-Orea, and F.A Domínguez-Pacheco, "Blood optical absorption of rats with hepatic damage and turmeric treatment: Methemoglobin analysis," J. Mol. Liq., vol. 291, 2019, pp. 1-5.

\section{AUTHORS PROFILE}

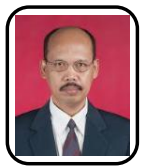

Unggul Pundjung Juswono, is a lecturer in Physics Department, University of Brawijaya, Malang, East Java, Indonesia. He is an expert in biophysics subject. The study is focused on environmental health.

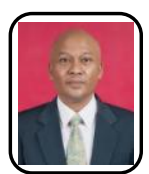

Arinto Y. P. Wardoyo, is a lecturer in Physics Department, University of Brawijaya, Malang, East Java, Indonesia. He is an expert in air quality and environmental physics subjects. His study is focused on environmental health.

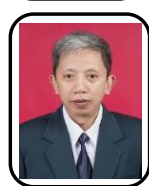

Chomsin S. Widodo, is a lecturer in Physics Department University of Brawijaya, Malang, East Java, Indonesia. He is an expert in biophysics subject.

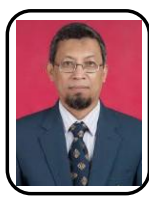

Johan A. E. Noor, is a lecturer in Physics Department, University of Brawijaya, Malang, East Java, Indonesia. He is an expert in biophysics subject. 
Didik R. Santoso, is a lecturer in Physics Department, University of Brawijaya, Malang, East Java, Indonesia. He is an expert in measurement system.

Gancang Saroja, is a lecturer in Physics Department, University of Brawijaya, Malang, East Java, Indonesia. He is an expert in material physics subject. 